\title{
Colombianos en el exterior: análisis comparativo de cuatro destinos a partir de censos de población
}

\author{
Andrés F. Castro Torres* \\ Ximena Canal Laiton**
}

Recepción: 24 de julio de 2017 Aceptación: 25 de noviembre de 2017

Resumen La descripción de las condiciones socioeconómicas y demográficas de la población emigrante constituye un primer paso para la formulación de políticas migratorias que favorezcan los beneficios y prevengan los detrimentos de saldos migratorios negativos. Después de 1950, estas consideraciones se hicieron pertinentes para países latinoamericanos que pasaron de ser receptores a emisores; Colombia no es la excepción. Haciendo uso de información censal reciente, este trabajo describe y compara las características de la población migrante colombiana y sus procesos de inserción cultural y material en Chile, Ecuador, Estados Unidos y España. Esta comparación permite observar un alto nivel de heterogeneidad entre las características de los migrantes, los procesos de inserción de los mismos y las experiencias migratorias de hombres y mujeres.

PALABRAS CLAVE: emigración, Colombia, inserción cultural, inserción estructural, característica de selección.

\section{Colombians abroad: a comparative analysis of four destinations using census data}

Abstract One of the first steps to be taken in the formulation of migration policies that will promote the benefits and prevent the harm of negative migratory balances is to describe the socioeconomic and demographic conditions of

\footnotetext{
* Investigador invitado en el Instituto Nacional de Estudios Demográficos de París (CZ) en temas de migración y fecundidad como parte de su tesis doctoral, candres@sas.upenn.edu

** Gestora de información del centro de datos e información del Sistema de Naciones Unidas en Colombia (Unidad de Manejo y Análisis de Información Colombia, UMAIC), canalaiton@gmail.com
} 
the emigrant population. Since 1950 the need to do this has been evident for Latin American countries that went from positive to negative migration balances; Colombia is no exception. Using recent census data from five countries, we describe and compare the characteristics of Colombian migrants and their experiences of cultural and material assimilation in Chile, Ecuador, the United States and Spain. This comparison shows a high level of cross-national heterogeneity in three aspects: the characteristics of the migrants, the processes of assimilation and the migratory experiences of men and women.

\section{Introduction}

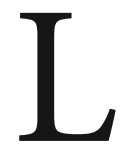

os cambios de dirección en los flujos migratorios de los países latinoamericanos después de los años cincuenta colocaron a la emigración como una dinámica preponderante en la región. Colombia no es la excepción (Durand, 2009; Donato, Hiskey, Durand, \& Massey, 2010). La importancia de este fenómeno es creciente debido al potencial que tiene de generar impactos tanto positivos como negativos a través de la circulación de remesas, así como de tipo económico, social y político, como lo han demostrado experiencias en otras regiones (Cohen, 2001; Levitt \& Lamba-Nieves, 2011; Careja \& Emmenegger, 2012). Así pues, comparar las condiciones socioeconómicas y demográficas de los emigrantes en diversos destinos constituye un primer paso hacia la comprensión de la dinámica migratoria y sus consecuencias potenciales. El presente trabajo es un aporte en esta dirección.

De acuerdo con Cárdenas y Mejía (2006), el 8 \% de los colombianos estaban viviendo en el exterior en 2005; una proporción considerable en comparación con las de otros países de la región (Guzmán, Rodríguez, Martínez, Contreras, \& González, 2006). A pesar de las diferencias entre las distintas estimaciones del total y la distribución de los colombianos en el exterior, todas coinciden en identificar los principales países receptores. Los tres principales han sido Venezuela, Estados Unidos y España. Estos tres países albergan aproximadamente el $85 \%$ del total de los emigrantes colombianos. El restante $15 \%$ se distribuye en destinos como Ecuador, Panamá, Francia y Canadá, países con al menos $1 \%$ de los emigrantes colombianos.

Con base en las estimaciones del Banco Mundial (Word Bank, 2011), se pueden distinguir dos tipos de destinos relevantes para la dinámica migratoria colombiana: 1) países con una cantidad importante de nacionales colombianos, producto de una larga historia migratoria; 2) países con cantidades menores de colombianos, que han crecido a tasas importantes en las últimas dos décadas. El cuadro 1 muestra estimaciones del total y el porcentaje del total de migrantes en los 16 países con mayor presencia de colombianos durante la década de los ochenta del siglo pasado y la primera del siglo 
XXI. La razón de cambio entre estas dos décadas señala el comportamiento reciente del flujo migratorio.

CUADRO 1. Total de migrantes colombianos, distribución porcentual y razón de cambio entre las dos décadas para los 16 principales destinos, según estimaciones del Banco Mundial, 2011

\begin{tabular}{|c|c|c|c|c|c|c|}
\hline \multirow{2}{*}{ País de recepción } & \multicolumn{2}{|c|}{ Total migrantes } & \multicolumn{2}{|c|}{ Porcentaje } & \multicolumn{2}{|c|}{ Razon $2000 / 1980$} \\
\hline & 1980-89 & $2000-10$ & 1980-89 & $2000-10$ & Totales & Porcentaje \\
\hline Venezuela & 911,180 & $1,235,488$ & 63.36 & 40.29 & 1.36 & 0.64 \\
\hline Estados Unidos & 334,948 & $1,066,038$ & 23.29 & 34.76 & 3.18 & 1.49 \\
\hline España & 5,563 & 281,495 & 0.39 & 9.18 & 50.60 & 23.73 \\
\hline Ecuador & 72,923 & 101,020 & 5.07 & 3.29 & 1.39 & 0.65 \\
\hline Panama & 24,534 & 43,690 & 1.71 & 1.42 & 1.78 & 0.84 \\
\hline Francia & 5,774 & 35,863 & 0.40 & 1.17 & 6.21 & 2.91 \\
\hline Canadá & 16,186 & 35,836 & 1.13 & 1.17 & 2.21 & 1.04 \\
\hline Alemania & 1,628 & 23,334 & 0.11 & 0.76 & 14.33 & 6.72 \\
\hline Inglaterra & 7,063 & 19,854 & 0.49 & 0.65 & 2.81 & 1.32 \\
\hline Holanda & 3,875 & 19,372 & 0.27 & 0.63 & 5.00 & 2.34 \\
\hline Aruba & 1,896 & 14,094 & 0.13 & 0.46 & 7.43 & 3.49 \\
\hline México & 6,536 & 12,434 & 0.45 & 0.41 & 1.90 & 0.89 \\
\hline Costa Rica & 2,050 & 11,807 & 0.14 & 0.39 & 5.76 & 2.70 \\
\hline República Dominicana & 5,674 & 11,454 & 0.39 & 0.37 & 2.02 & 0.95 \\
\hline Brasil & 2,986 & 8,316 & 0.21 & 0.27 & 2.78 & 1.31 \\
\hline Chile & 2,042 & 7,815 & 0.14 & 0.25 & 3.83 & 1.79 \\
\hline Totales/mediana & $1,404,858$ & $2,927,910$ & & & 3.00 & 1.41 \\
\hline
\end{tabular}

$\mathrm{Al}$ grupo de destinos con larga historia migratoria pertenecen Venezuela, Ecuador, Panamá y Canadá, todos con más de 30 mil colombianos al comienzo de este siglo y una razón de cambio inferior a la mediana entre los 16 países (1.41). Al grupo de países con incrementos importantes en las últimas décadas pertenecen España, Francia, Alemania, Holanda, Costa Rica y Chile, todos con razón de cambio superior a la mediana. El caso de Estados Unidos de América (EUA) es particular, pues a pesar de tener una tasa de crecimiento ligeramente superior a la mediana - lo que lo ubicaría como un país del segundo grupo-, históricamente ha sido uno de los principales destinos de los colombianos, superado solamente por Venezuela. La disponibilidad de información sobre inmigrantes en estos 16 países no es homogénea, por lo que un estudio comparativo sobre las características demográficas y condiciones socioeconómicas de los migrantes colombianos solo es posible sobre un subgrupo de países. 
En el presente estudio se analizan los casos de Ecuador, España, Estados Unidos y Chile porque para estos cuatro países se cuenta con un censo de población reciente - primera década del siglo XXI- que permite identificar dos características fundamentales para estudiar aspectos de la inserción de migrantes: país de nacimiento y año de llegada al país de recepción. Si bien esta selección puede parecer arbitraria, consideramos que tener información comparable utilizando datos de distintos destinos es más importante para nuestro interés de investigación que tener una cobertura más amplia sin posibilidades reales de comparar la situación de los colombianos en cada lugar. Adicionalmente, estos países ofrecen un amplio espectro de contextos de recepción, pues difieren en términos de historia migratoria y proximidad geográfica, económica y cultural. Ecuador y Estados Unidos tienen una amplia e importante historia migratoria con Colombia, pero solo Ecuador tiene límites e idioma comunes. Chile y España, por su parte, constituyen destinos que han venido creciendo en los últimos años, con importantes diferencias en términos culturales y de desarrollo económico.

Dada esta restricción en la información, nuestro interés se limita a proveer una descripción comparativa de la población colombiana en estos cuatro destinos, sin pretensiones de generalización pero sí realizando un esfuerzo teórico que permite derivar implicaciones sobre la forma de entender la experiencia migratoria y sus principales aspectos distintivos, entre ellos las diferencias de género asociadas a ella. De esta forma, el presente artículo hace dos contribuciones principales. Primera, presenta una descripción de la población colombiana residente en el exterior a partir de datos censales, lo que le da un carácter representativo, en el sentido estadístico del término. Segunda, utiliza conceptos sociológicos para la interpretación de las diferencias entre las características de las poblaciones de no migrantes y las de la población migrante de origen colombiano.

\section{Revisión bibliográfica}

Los estudios de migración colombiana reciente se han enfocado en el impacto de la experiencia migratoria en los hogares de origen (Cárdenas, Medina, \& Trejos, 2010) y en la constitución de comunidades colombianas en países como el Reino Unido, España (Bermúdez, 2006; Mcilwaine, 2005) y EUA (Guarnizo, Sánchez, \& Roach, 1999). En materia de impactos en el hogar de origen, Cárdenas et al. (2010) reportaron efectos importantes de la experiencia migratoria en el gasto total per cápita, especialmente en lo relacionado con la salud y la educación; pero no encontraron ningún efecto significativo de la migración sobre la participación de la mano de obra del hogar ni sobre la asistencia a la escuela de la población en edad escolar. 
Otros estudios han abordado el tema de la migración de retorno y las remesas. Mejía (2010, 2012), por ejemplo, reportó una alta carga de los primeros retornos y encontró que las mujeres y los migrantes con un nivel de educación más alto tienden a pasar más tiempo en el extranjero, pero mantienen fuertes sus intenciones de regresar. Medina y Posso (2009) reportaron resultados similares, enfatizando la selección negativa en términos de nivel educativo de los colombianos que regresaron de EUA entre 1990 y 2005. Por su parte, la Organización Internacional para las Migraciones (Garay \& Rodríguez, 2005; Ramírez, Zuluaga, \& Perilla, 2010) y Álvarez Llanos (2012) se enfocaron en el impacto económico de las remesas y el ordenamiento de las finanzas de los migrantes, apuntando a que los principales propósitos de ahorrar y enviar dinero a su familia son pagar el préstamo que les permitió emigrar, y comprar vivienda en el país de destino o en Colombia. En cuanto a los datos y métodos utilizados en estos estudios, la mayoría proviene de datos del censo colombiano, más algunas encuestas especializadas realizadas en Colombia o en el exterior. Se basan en estadísticas descriptivas para comparar la población y utilizan modelos econométricos para medir el impacto de la experiencia migratoria o la probabilidad de retornar.

Por otro lado, los estudios de los colombianos que viven en EUA o en los países más desarrollados (PMD) se caracterizan por analizar aspectos específicos como la participación política, el desarrollo de actividades transnacionales o el desarrollo organizacional (Guarnizo et al., 1999; Mejía, 2006; Bermúdez, 2006). En estos estudios, la población colombiana que va a los PMD está compuesta por personas de clase media, algunas de ellas con títulos universitarios, pero mayormente con niveles educativos más bajos. En términos generales, el contexto de recepción ofrecido por EUA, España y el Reino Unido es similar en el sentido de que el principal motor de los flujos migratorios procedentes de Colombia es el mercado de trabajo. Esta característica, más la distancia cultural y geográfica entre los países, hace una diferencia importante entre los contextos de recepción ofrecidos por los PMD y el contexto de recepción en países de la misma región.

Un conjunto importante de la literatura ha examinado a la población colombiana en Chile y Argentina, la primera como un destino reciente y la segunda como uno más tradicional. Viuche (2015) reportó que los migrantes colombianos en Santiago de Chile a menudo se enfrentan a la discriminación social y la explotación en el mercado de trabajo. En un tono similar, Segovia y Lufin (2013) concluyen, sobre los afrocolombianos en la región norteña de Antofagasta, Chile, que las diferencias culturales los hacen "[...] objetos potenciales de segmentación social y segregación en una comunidad receptora que ya muestra rasgos significativos de intolerancia y estigmatización hacia estos nuevos inmigrantes". Ambos casos reflejan la importancia del contexto de recepción y de las características del inmigrante en la determinación de sus condiciones socioeconómicas. A pesar de que la evidencia no es representativa de toda la 
población inmigrante, esta realidad se presenta con frecuencia en trabajadores no calificados con bajos niveles de educación.

La relación entre Colombia y sus dos vecinos más cercanos, Ecuador y Venezuela, merece especial atención. La migración en estos casos tiene un importante componente rural y una estrecha relación con las redes de comercio fronterizo (perilla) y las dinámicas del desplazamiento forzado colombiano (Postgrado en ciencias del desarrollo, 2008). Sin embargo, la cuestión sobre la asimilación de los colombianos en estos países sigue sin respuesta. Dada la historia común y los lazos duraderos entre las tres naciones, los estudios sobre la asimilación de los colombianos en Ecuador y Venezuela pueden estar en la literatura general sobre la historia de cada país y no en artículos específicos de tema migratorio. Esta literatura excede el alcance del presente trabajo.

Nuestra evaluación de los trabajos citados indica que hay una brecha en la literatura sobre la emigración colombiana en términos de las condiciones generales de su inserción en los distintos lugares de acogida. Si bien existen en ella descripciones de la población migrante colombiana, por lo general no están basadas en fuentes representativas, en el sentido estadístico del término. Cuando los estudios utilizan información representativa, generalmente se limitan a la descripción de perfiles socioeconómicos y demográficos, sin realizar comparaciones entre diversos contextos de recepción. Adicionalmente, consideramos necesario un esfuerzo teórico para la comprensión de estas dinámicas que vaya más allá de la descripción y permita derivar implicaciones generales sobre la experiencia migratoria.

\section{Teoría y conceptos}

Entendemos la experiencia migratoria en dos niveles: individual y poblacional. A nivel individual, consideramos que el cambio de residencia de un país a otro trae consigo modificaciones importantes en la forma de vida de la persona y la familia involucradas. La magnitud de esos cambios depende, entre otros factores, de la similitud o discrepancia entre el lugar de origen y el lugar de destino en aspectos culturales y materiales. Los culturales incluyen el idioma, las prácticas matrimoniales y los valores prevalentes en la sociedad de acogida, entre otros. Los aspectos materiales incluyen las condiciones del mercado laboral, las formas de acceso a bienes y servicios, el acceso a la educación. El tiempo de permanencia en el lugar de destino favorece la inserción de los migrantes en las dinámicas propias del país de acogida en forma diferenciada, según la estructura de clases en el lugar de destino y la clase a la que pertenece la persona o familia migrante (Portes \& Zhou, 1993). 
En el aspecto poblacional, la migración es un fenómeno demográfico que da lugar a la existencia de subpoblaciones dentro de un territorio nacional. Estas subpoblaciones pueden definirse de múltiples maneras, por ejemplo a través del país de nacimiento (nativos $v s$. nacidos en el exterior) o la nacionalidad (nacional $v s$. extranjero). Adicionalmente, la población nacida fuera del país puede clasificarse de acuerdo con características migratorias como la edad a la migración (antes de los 15, después de los 15) o el tiempo de residencia en el país de destino (menos de cuatro años, más de cuatro años). La comparación de indicadores socioeconómicos y demográficos entre las distintas subpoblaciones de personas nacidas fuera de un país y la población nativa permite analizar las dinámicas de inserción de la población migrante (cuando se compara a los migrantes con bastante tiempo en el lugar de destino) y las características distintivas de la población en el momento migratorio (cuando se compara a los migrantes recientes). A estas características las denominamos características de selección porque son indicativas de las condiciones que diferencian a quienes migraron de quienes no lo hicieron. Así, los dos conceptos centrales del presente trabajo son: inserción (cultural y material) y características de selección de la población migrante.

Los conceptos de inserción cultural y de inserción material se utilizan en el presente trabajo para interpretar las diferencias en las características demográficas y socioeconómicas de la población nativa de las que presenta la población migrante de origen colombiano. Debido a que estos conceptos fueron propuestos para el contexto de las migraciones del siglo pasado hacia EUA, su transferencia al contexto de la migración colombiana requiere algunas adaptaciones (Feagin \& Feagin, 2003). Por inserción cultural entendemos el nivel de similitud entre dos poblaciones en indicadores asociados a las formas de organización de la vida familiar (prevalencia del matrimonio, número de familias por vivienda, tipos de hogar y diferencias entre sexos en dichos indicadores). En la medida en que la mayoría de las sociedades - si no todasrequieren una institución que, sobre la base de las reglas de parentesco, permita la producción y reproducción de relaciones sociales (Héritier, 1996), los indicadores mencionados pueden ser entendidos como reflejo de los fundamentos culturales de una sociedad. Entendemos por inserción material el nivel de similitud entre las poblaciones en indicadores relacionados con la dinámica de producción y consumo, es decir, las dinámicas del mercado laboral y el acceso a bienes y servicios. Los indicadores utilizados para esta dimensión fueron: relación de propiedad con la vivienda, tipo de ocupación y máximo nivel educativo alcanzado.

La interacción entre las dimensiones cultural y material se ha utilizado de manera provechosa en teorías sobre las causas y consecuencias de los cambios demográficos y sociales (Bourdieu, 1996; Portes, 2006; Johnson-Hanks, Bachach, Morgan, \& Kohler, 2011). La complejidad de estas teorías demanda información muy detallada para su aplicación, por lo que son incompatibles con estrategias empíricas basadas en censos 
de población, en particular sobre poblaciones migrantes. Sin embargo, consideramos que analizar en forma simultánea variables asociadas a cada ámbito constituye un primer paso hacia una compresión más precisa de las condiciones de los colombianos en el exterior.

Desde esta perspectiva, nuestro interés es comparar la población de migrantes colombianos con las poblaciones nativas de los cuatro países de recepción y la población de no migrantes en Colombia en términos culturales y materiales, como una forma de aproximarnos a las posiciones sociales que ocupan a los colombianos en cada una de las sociedades de acogida en dos momentos distintos: al poco tiempo de llegar al país de recepción y tiempo después de haber realizado el movimiento migratorio.

\section{Datos y métodos}

\section{Censos y subpoblaciones de interés}

Utilizamos muestras censales de comienzos del siglo XXI en cada uno de los cinco países, disponibles en la plataforma IPUMS-I (Minnesota Population Center, 2015). ${ }^{1}$ Identificamos a la población migrante a través del país de nacimiento (BPLCOUNTRY) y su año de llegada al país por medio del año de la emigración (YRIMM). La diferencia entre el año del censo (YEAR) y el año de llegada al país nos permite identificar el tiempo desde la emigración. Con base en esta diferencia, distinguimos dos tipos de migrantes: aquellos con menos de cuatro años en el país de recepción, a los que denominamos "migrantes recientes", y las personas con más de cuatro años en el país de recepción, consideradas "migrantes antiguos". La hipótesis detrás de esta distinción es que, en presencia de canales de inserción material y cultural, la población de migrantes antiguos debe parecerse más a la población nativa que la población de migrantes recientes. Por su parte, el grupo de migrantes recientes refleja condiciones más cercanas al momento migratorio; en otras palabras, las características de este grupo se aproximan a las características de selección.

Estamos conscientes de que esta distinción no equivale a tener información longitudinal sobre personas migrantes (antes, durante y después del movimiento

1 Los autores agradecen a las distintas oficinas de estadísticas nacionales que, a través de la plataforma citada, permiten el acceso a la información que se analiza en este artículo: Instituto Nacional de Estadística-Chile, Departamento Nacional de Estadística-Colombia, Instituto Nacional de Estadísticas y Censos-Ecuador, Instituto Nacional de Estadística-España, Oficina Nacional de Censos-Estados Unidos. 
migratorio). Nuestros resultados y conclusiones deben ser tomados con cautela principalmente por tres razones. Primera, no existe información antes de la migración, por lo que las características de selección son aproximadas. Segunda, los migrantes antiguos y recientes no solo difieren en la cantidad de tiempo que llevan en el país de acogida, sino también en el periodo de ingreso al mismo, y posiblemente en la edad a la migración. Tercera, nuestro análisis no puede identificar a las personas retornadas; de ahí que nuestras comparaciones pueden estar contaminadas, por lo que en la literatura estadounidense se conoce como el settlement-bias (Beauchemin, 2014). A pesar de esto creemos que, en ausencia de información longitudinal, esta comparación puede ofrecer indicaciones importantes sobre las dinámicas de selección e inserción debido a que los flujos migratorios tienden a concentrarse en ciertas edades y en las décadas recientes. El cuadro A1 de los apéndices muestra la distribución de los migrantes según el año de ingreso al país. La proporción de los que llegaron antes de 1970 es baja, lo cual indica que estos migrantes de mayor antigüedad no pueden sesgar fuertemente los resultados.

Nuestro análisis separa por sexo (SEX) y a los migrantes nacidos en países distintos de Colombia en dos grupos: personas nacidas en países latinoamericanos (América Latina) y personas nacidas en el resto de los países (otros). El cuadro 2 presenta los tamaños de muestra de cada una de las subpoblaciones.

Los totales y la estructura etaria de las poblaciones se estimaron utilizando la totalidad de la muestra. El análisis de las dinámicas de inserción material y cultural, por su parte, se realizó sobre la población entre 20 y 65 años. Las variables seleccionadas para el análisis pertenecen a dos grupos. El primero incluye variables que reflejan formas de organización de la vida en familia y dentro del hogar: estado civil (MARST), cantidad de familias dentro de la vivienda (NFAMS) y la posición de la persona con respecto al jefe(a) de hogar (RELATE). Este primer grupo de variables corresponde a la dimensión cultural, el segundo refleja condiciones materiales de inserción en la sociedad de recepción. Este grupo incluye: relación de propiedad con la vivienda (OWNERSHP), tipo de ocupación (combinación de las variables CLASSWK y OCCISCO) y máximo nivel educativo alcanzado (EDATTAIN). Algunas de las categorías de las variables analizadas fueron recodificadas para obtener indicadores similares en cada país garantizando tamaños de muestra no inferiores al $2 \%$ en cada una de ellas.

\section{Estandarización de indicadores}

Para cada una de las subpoblaciones definidas en el cuadro 2 se calcularon las proporciones en cada categoría de las variables de interés por grupos quinquenales de edad. Estas proporciones específicas por grupos etarios fueron utilizadas para calcular 


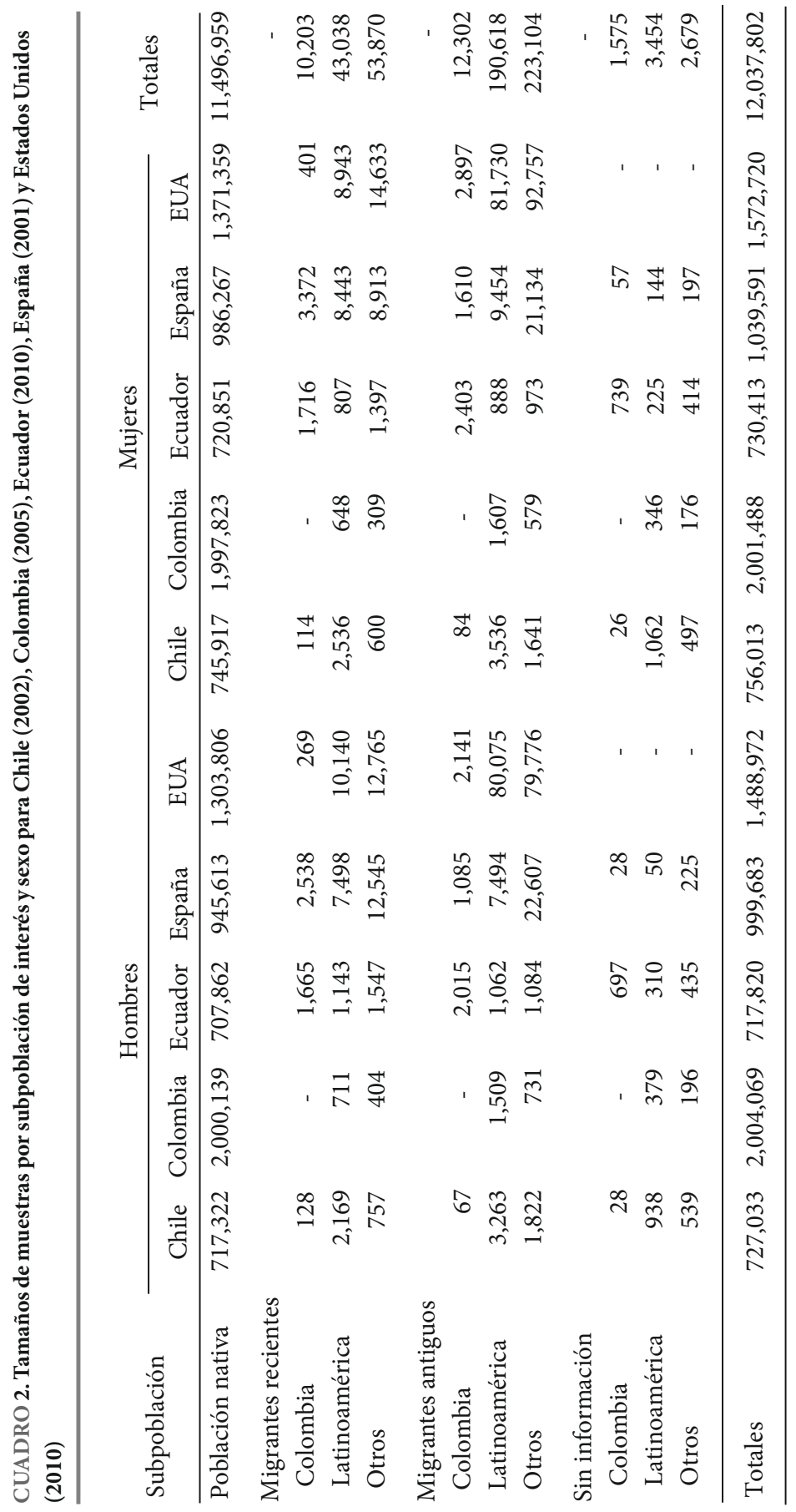


proporciones globales estandarizadas (PGE) para cada subpoblación utilizando la estructura etaria de la población nativa. La ecuación siguiente representa en forma genérica el proceso de estandarización.

$$
P G E^{j}=\sum_{x=20}^{60} \quad{ }_{n} P_{x}^{j} *{ }_{n} C_{x}
$$

$P G E^{j}$ es la proporción global estandarizada para la subpoblación $j,{ }_{n} P_{x}^{j}$ es la proporción específica para las personas de la subpoblación $j$ entre $x$ y $x+n$ años de edad $\mathrm{y}_{n} C_{x}$ es la proporción de nativos del mismo grupo etario. La suma de los valores de ${ }_{n} C_{x}$ es igual a uno.

Este proceso de estandarización es necesario por dos razones: primera, la estructura etaria de la población migrante y de la población nativa difiere significativamente; segunda, los indicadores utilizados como variables de inserción cultural y material están correlacionados con la edad. Por ejemplo, la proporción de personas dentro de una unión marital tiene forma de $U$ invertida con respecto a la edad. En forma análoga, la probabilidad de ser dueño de una vivienda aumenta con la edad debido a que su compra requiere de un proceso de acumulación previo. En suma, las proporciones estandarizadas son indicadores comparables entre las distintas subpoblaciones pues reflejan la prevalencia de una característica al tiempo que controlan los posibles sesgos debidos a la estructura etaria. Para facilitar la comparación, las PGE se dividieron entre la PGE de la población nativa. Esta razón de proporciones indica, entonces, el nivel de similitud o de discrepancia entre las subpoblaciones y la población nativa.

\section{Resultados}

\section{Totales, distribución por sexo y temporalidad de la migración}

En los cuatro países de interés, el total de migrantes colombianos a comienzos del siglo XXI es de alrededor de 918 mil personas. El cuadro 3 contiene la estimación del total de personas para cada subpoblación y las razones de sexo.

La mayoría de los emigrantes colombianos se encuentran en EUA (664 mil) y España (172 mil); el primero es el destino donde predominan los migrantes antiguos (87\%) y en el segundo predominan los migrantes recientes (69\%). Chile tiene la menor cantidad de colombianos (4 mil), que en su mayoría son migrantes recientes (62\%). En Ecuador, con aproximadamente 78 mil colombianos, predomina la migración antigua (56\%). Se trata de dos destinos de emergencia reciente y dos de historia migratoria antigua. 


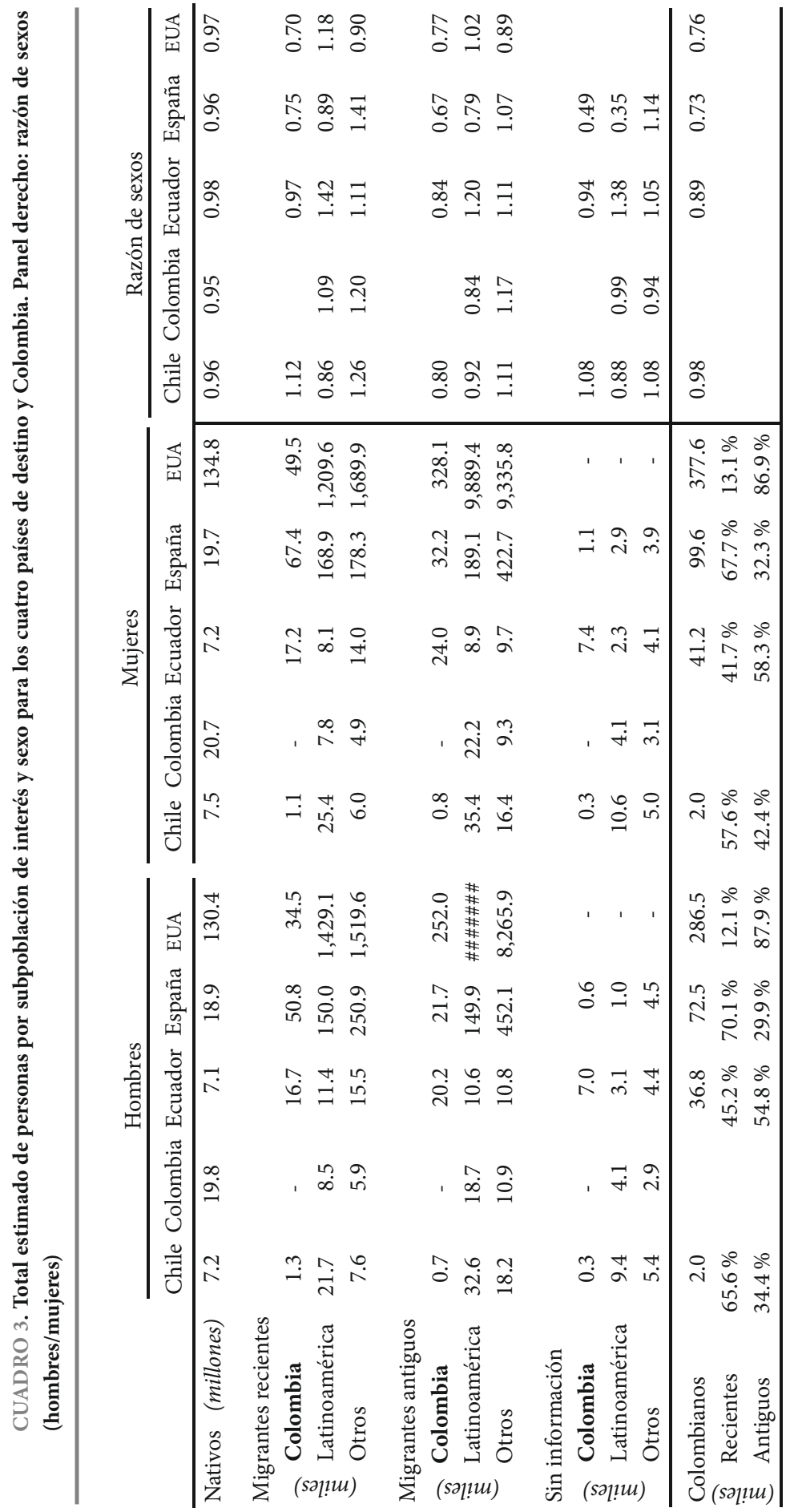


Del total de personas migrantes, 397 mil son hombres y 520 mil mujeres, para una razón de sexos de 0.76 . Las mujeres colombianas exceden en cantidad a los hombres colombianos en casi todos los cuatro destinos y tipos de migración. El carácter femenino del fenómeno migratorio colombiano es fuerte en España, donde la razón de sexos es de 0.75 entre migrantes recientes y de 0.67 entre migrantes antiguos. Solo entre los migrantes recientes (y sin información) en Chile el número de hombres supera al de mujeres. Esta característica contrasta con la razón de sexos entre los migrantes del resto de países latinoamericanos. Entre los migrantes de este grupo la razón de sexos es menor que uno en Chile y España, y mayor que uno en Ecuador y EUA. En cuanto al resto de países (otros), los hombres son el grupo dominante en la dinámica migratoria en todos los destinos salvo en EUA.

La estructura etaria de la población migrante colombiana presenta una gran heterogeneidad en estos cuatro destinos. La figura 1 muestra en forma comparativa la distribución de la población por edad y sexo para dos subpoblaciones en cada país.

La estructura de la población nativa en Chile y Ecuador es de forma triangular. La base de la pirámide en Chile es más delgada que en Ecuador porque la fecundidad ha sido menor en el país sureño. La mayoría de los colombianos que residen en Chile son adultos entre los 20 y 35 años. El segundo grupo de mayor presencia en este país son los menores de edad, lo cual hace que la población colombiana en Chile sea más joven que la nativa. En Ecuador, la población de colombianos también se concentra entre los 25 y 35 años, sin embargo su distribución es más dispersa entre los demás grupos etarios; en consecuencia, la población migrante de colombianos en Ecuador presenta un mayor grado de envejecimiento que la población nativa.

España y EUA tienen proporciones más altas en los grupos etarios superiores. Hay dos diferencias importantes entre las estructuras etarias de estos dos países. Primera, la base de la pirámide de EUA es considerablemente más ancha que la de España debido a las brechas de fecundidad entre los dos países (Billari \& Kohler, 2004). Segunda —en parte a consecuencia de esta brecha-, España tiene una mayor proporción de la población en la parte superior de la pirámide, es decir, es una población con más alto nivel de envejecimiento. La población de colombianos en EUA se concentra entre los 35 y 45 años. Adicionalmente, la base de la pirámide de migrantes es delgada y casi inexistente por debajo de los cinco años de edad. En cuanto a las edades superiores, las dos distribuciones son similares. En el caso de España, la población se concentra en edades más tempranas, de 25 a 35 años, y la base de la población es mucho más gruesa que la base de la población nativa. Finalmente, la proporción de colombianos por encima de los 50 años es muy baja. 
Chile 2002

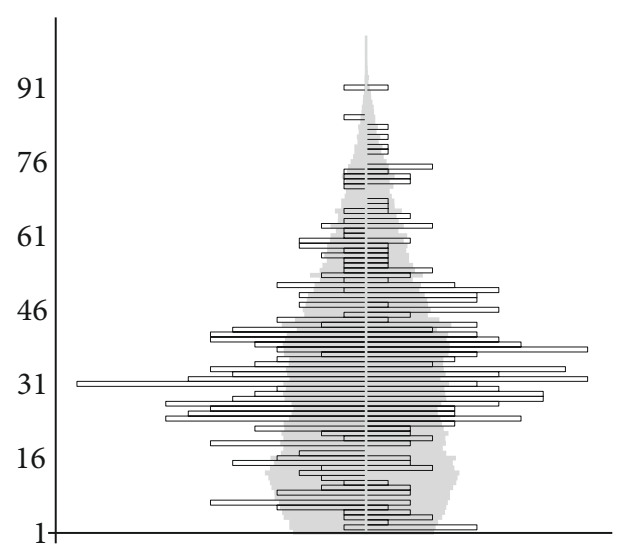

EUA 2005

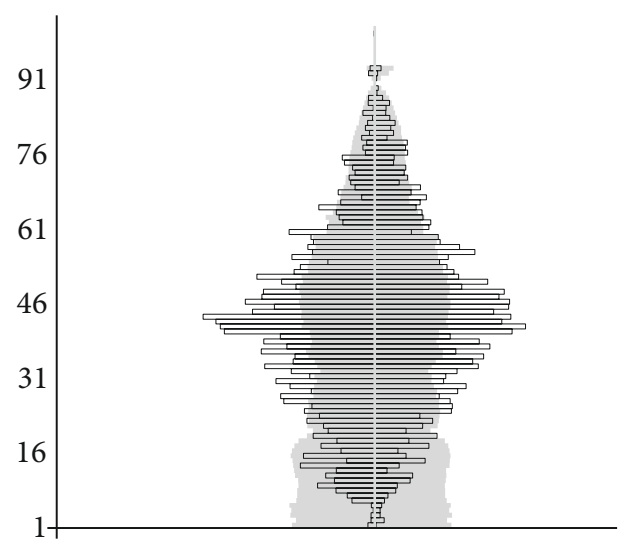

Colombianos
Ecuador 2010

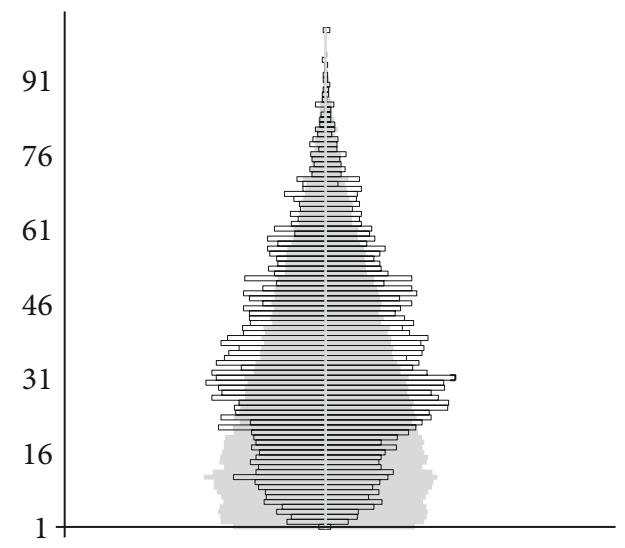

España 2001

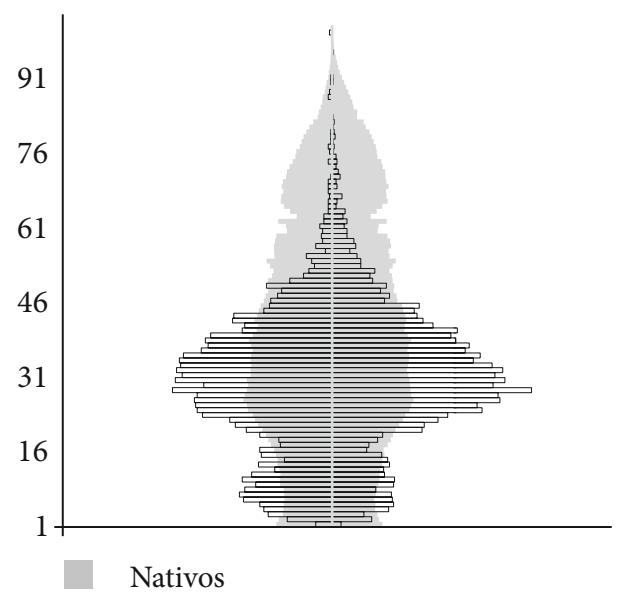

Divergencia entre los cuatro contextos de recepción: interacción entre proximidad geográfica, legado colonial y nivel de desarrollo

A las diferencias en la estructura etaria se suman las diferencias en términos culturales y estructurales de los lugares de recepción y origen. La propensión de la población migrante a aproximarse en sus indicadores socioeconómicos y demográficos a la 
población nativa es mediada por el nivel de discrepancia inicial entre una sociedad y la otra. Es más probable que los migrantes colombianos en Ecuador sean similares a la población nativa que los migrantes colombianos en EUA, en primer lugar, porque las diferencias entre la población nativa colombiana y la estadounidense son mayores que las diferencias entre las poblaciones nativas de los dos países latinoamericanos. En segundo lugar, porque las características de selección de los migrantes que van hacia cada destino pueden variar. El cuadro 4 contiene el perfil de cada uno de los cinco países en términos de estado civil, tipo de hogar, relación de propiedad con la vivienda, ocupación y nivel educativo. Estos indicadores permiten establecer el nivel de similitud o discrepancia entre Colombia y cada uno de los cuatro destinos que se estudiaron.

En términos de estado civil y formas de organización del hogar, se ve una clara similitud entre los países latinoamericanos y una distancia importante con EUA y España, siendo más marcada con respecto al país europeo debido a la alta prevalencia de formas tradicionales de familia. En EUA y España la proporción de hombres casados es menor que en los países latinoamericanos. El caso de las mujeres es distinto, España presenta la mayor proporción de mujeres en unión marital con respecto a los demás países. Sin embargo, la diferencia entre los países latinoamericanos y EUA se mantiene. En cuanto a la prevalencia de hogares multifamiliares (más de una familia en la vivienda), existen importantes diferencias entre los países, desde niveles de $3.4 \%$ en España hasta $9.9 \%$ en Colombia. En cuanto a la proporción de personas que residen en un hogar cuyo jefe o jefa no pertenece a su núcleo familiar - padre/madre, esposo(a) o hijo(a) - , se observan niveles bajos en España y muy similares entre los restantes países tanto entre los hombres como entre las mujeres.

Los indicadores de vivienda, ocupación y nivel educativo reflejan las diferencias en términos de desarrollo e ingreso entre los cinco países. La proporción de propietarios es alta en Chile, España y EUA, y se encuentra por debajo del $70 \%$ en Ecuador y Colombia. No existen diferencias marcadas entre hombres y mujeres en este rubro. En cuanto a la proporción de asalariados, entre los hombres existen tres niveles: alta proporción de personas asalariadas (EUA, 78 \%), nivel intermedio (Chile y España, 64 $\%$ y $62 \%$, respectivamente) y nivel bajo (tanto en Colombia como en Ecuador, $57 \%$ ). En el caso de las mujeres, estos tres niveles persisten con una brecha importante con respecto a los hombres en cuatro de los cinco países: Ecuador, Colombia, Chile y España. En ellos la proporción de mujeres asalariadas es aproximadamente la mitad de la proporción entre los hombres, EUA es la excepción con proporciones de asalariados(as) casi idénticas. En cuanto a la proporción de empleadores y trabajadores por cuenta propia, las diferencias tanto entre los países como entre los sexos en el interior de cada país son importantes. Ecuador y Colombia tienen las proporciones más altas en esta categoría, seguidos por Chile y España. Finalmente, EUA tiene la proporción 


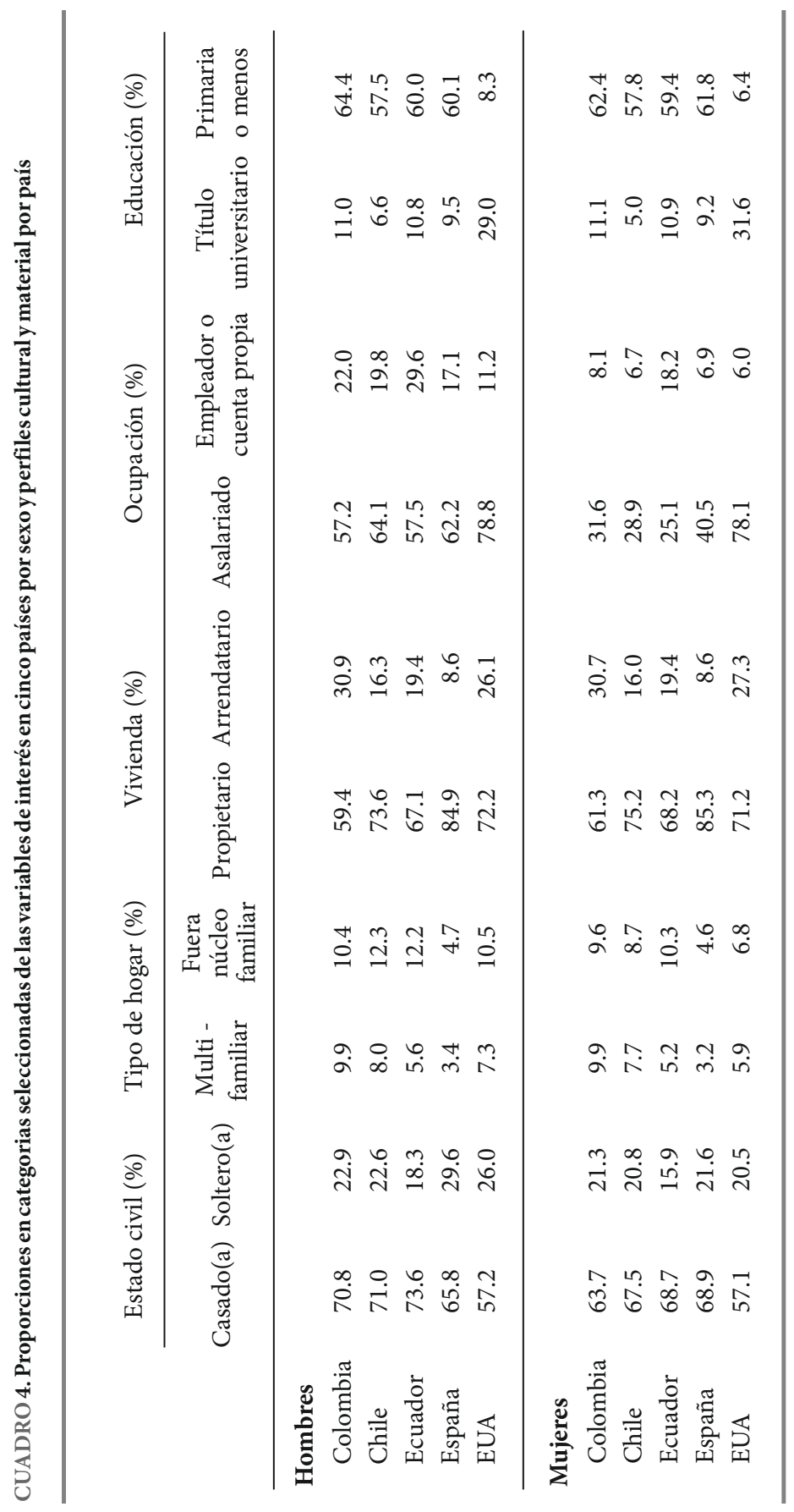


más baja (11\%). Entre las mujeres la proporción de empleadoras y trabajadoras por cuenta propia es sustancialmente más baja que la proporción entre los hombres (entre $38 \%$ y $66 \%$ más baja).

En términos de nivel educativo, EUA presenta mejores indicadores que los demás países. Casi un tercio de la población del país norteamericano tiene estudios universitarios, mientras que en los demás países esta proporción apenas supera el $10 \%$. Consecuentemente, la proporción de personas con educación primaria o menos es alta en Ecuador, Colombia, España y Chile. Las diferencias entre hombre y mujeres en términos de nivel educativo son mayores en EUA y en Chile, en los demás países los porcentajes por nivel educativo alcanzado son similares en los dos sexos.

En síntesis, Ecuador tiene un perfil cultural y económico cercano al perfil colombiano, seguido por Chile y España. El país sureño se distingue de Colombia por su nivel de desarrollo económico más elevado. Por su parte, la proximidad entre Colombia y España, en términos culturales, está asociada al legado colonial que el país europeo tiene en América Latina, y su distanciamiento a las recientes dinámicas divergentes en términos de cambios en la familia (Acosta, 2003; Kohler \& Anderson, 2016). El país más distante en estas dos dimensiones es EUA, lo que se suma al hecho de que es el único país con un idioma oficial distinto del español. Estas distancias relativas entre las poblaciones nativas de cada país llevarían a pensar que tanto las características de los migrantes colombianos en cada destino como sus procesos de inserción en cada sociedad deben variar de acuerdo con el destino. Por ejemplo, en términos de la estructura etaria, la población colombiana en los destinos de emergencia reciente (Chile y España) es más joven que la población nativa, lo que podría significar mayores obstáculos en los procesos de inserción cultural y quizás más posibilidades en términos de inserción en el mercado laboral. Lo contrario es cierto en los dos destinos con una historia migratoria más antigua, donde las redes migratorias pueden favorecer la inserción.

En las siguientes secciones se presentan los perfiles de los cuatro países de recepción junto con los perfiles de las poblaciones de colombianos no migrantes, colombianos migrantes, migrantes de otros países latinoamericanos y migrantes del resto del mundo. Estos perfiles fueron calculados usando proporciones globales estandarizadas (PGE) con la estructura etaria de la población nativa para garantizar la comparabilidad. Los cuadros del 5 al 8 presentan los porcentajes en categorías seleccionadas de las variables de interés para la población nativa de hombres (panel superior) y de mujeres (panel inferior). Para cada una de las subpoblaciones de interés, las tablas presentan la razón entre la PGE de la subpoblación y la proporción de la población nativa respectiva. 


\section{Ecuador: país con historia común y alta integración cultural y material}

En términos de estado civil, los migrantes recientes colombianos en Ecuador no difieren mucho de la población nativa ecuatoriana y son muy similares a la población no migrante de Colombia. La PGE de hombres y mujeres casadas es menor entre la población de origen colombiano que entre la población ecuatoriana; sin embargo, esta diferencia no es muy alta: $5 \%$ y $7 \%$ para hombres y mujeres, respectivamente. Tanto para hombres como para mujeres, la probabilidad de estar soltero es mayor comparada con la población nativa ( 8 \% y $30 \%$ menor, respectivamente). En contraste, las diferencias en la PGE de hogares multifamiliares son grandes y mucho más marcadas entre las mujeres. Si bien la prevalencia de hogares multifamiliares en Colombia es casi el doble que en Ecuador, entre los inmigrantes es 3.5 (hombres) y 4.3 (mujeres) veces mayor. En forma similar, la PGE de hombres y mujeres que residen en hogares cuyo jefe no pertenece a su núcleo familiar es dos y tres veces mayor entre los inmigrantes.

En cuanto a indicadores económicos, tanto hombres como mujeres inmigrantes recientes son menos propensos a ser propietarios de la vivienda en la que residen y mucho más propensos a ser arrendatarios. Las diferencias entre los sexos en estos indicadores son prácticamente nulas. Por el contrario, en términos de ocupación existen diferencias entre los sexos que vale la pena destacar. Comparados con la población nativa, los hombres colombianos tienen una menor probabilidad de ser empleadores o trabajadores por cuenta propia; sin embargo, esta probabilidad es más alta si se la compara con la probabilidad de ser empleador o trabajar por cuenta propia en Colombia. Entre las mujeres migrantes la probabilidad de ser asalariadas es menor cualquiera que sea el grupo de referencia (población nativa de origen o destino), lo contrario es cierto para la proporción de mujeres empleadoras o trabajadoras por cuenta propia. En términos educativos, la proporción de migrantes con título universitario es mayor que la proporción observada en ambas poblaciones nativas, pero esta diferencia no es muy grande (razón de proporciones 1.24 para hombres y 1.04 para mujeres). En forma análoga, una menor proporción entre los migrantes colombianos, tanto hombres como mujeres, tiene educación primaria o menos si se los compara con los no migrantes en ambos países. En síntesis, si bien hay diferencias entre las poblaciones de no migrantes y migrantes recientes colombianos, estas diferencias solo son grandes en términos del tipo de hogar y de la relación de propiedad con la vivienda.

$\mathrm{Al}$ analizar estas mismas características entre los migrantes antiguos se observa una dinámica de convergencia - con diferencias importantes entre los sexos- a medida que las diferencias entre las PGE disminuyen. Los hombres migrantes antiguos son muy similares a la población nativa en cuanto a la PGE de casados y solteros, mientras que entre las mujeres persisten diferencias superiores al $10 \%$ en estas dos 


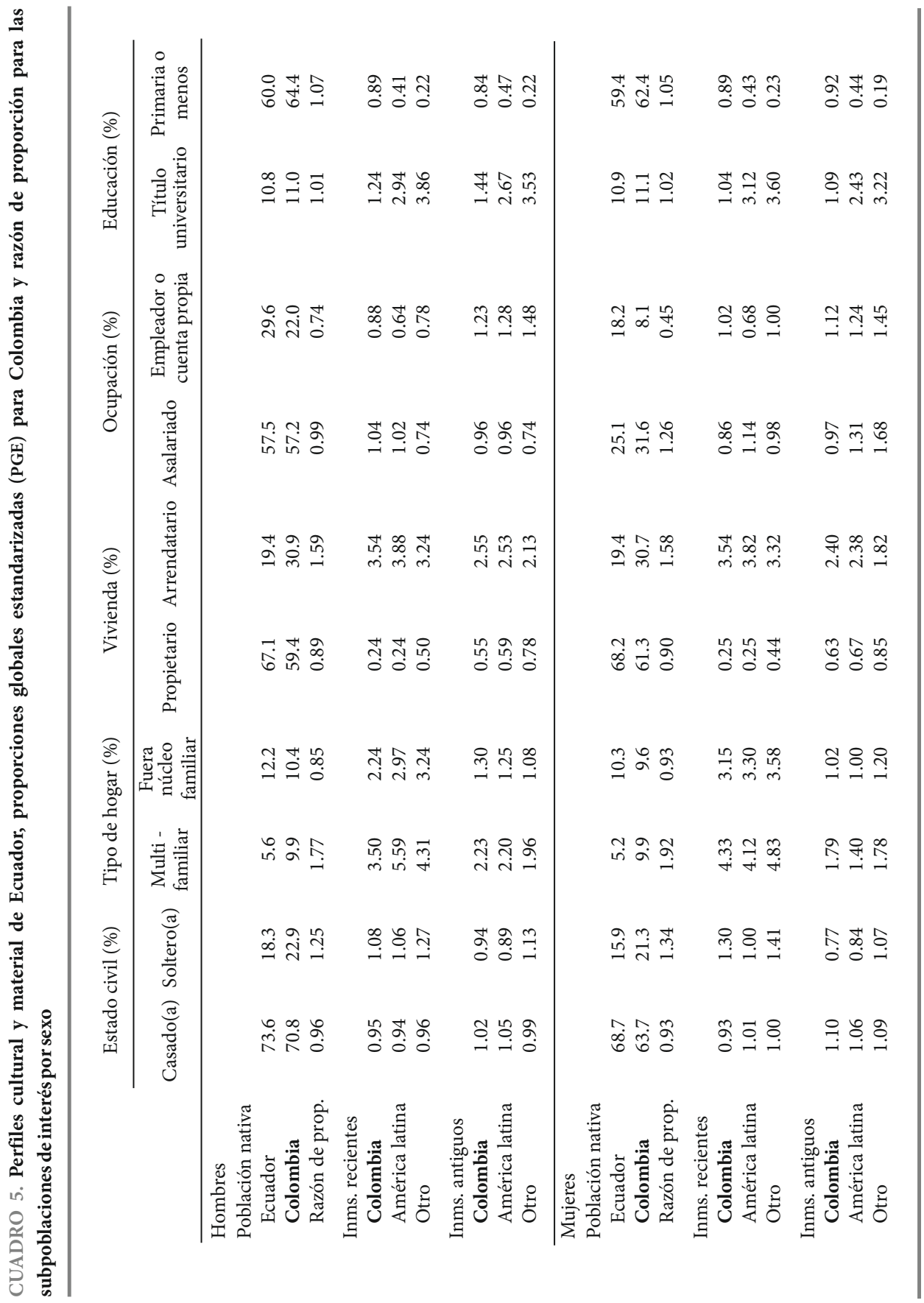


categorías. La razón de proporciones de hogares multifamiliares sigue siendo mayor que uno para hombres y mujeres, pero son menores comparadas con las de migrantes recientes. Esto indica que, con el paso del tiempo, las formas de organización de los hogares entre los inmigrantes se aproximan a las de la población nativa, sin llegar a ser idénticas.

En forma similar, la razón de proporciones aumenta para el indicador de propiedad de la vivienda y disminuye para la proporción de personas que viven en arriendo cuando se compara a migrantes recientes con antiguos. En ambos casos la razón de proporciones se mantiene lejos de la unidad, lo cual indica que las diferencias en cuanto a propiedad de la vivienda entre migrantes y población nativa persisten y son al menos del orden del $50 \%$ y $40 \%$ para hombres y mujeres, respectivamente. En otras palabras, en comparación con la población nativa, la proporción de propietarios entre migrantes antiguos es $50 \%$ y $40 \%$ más pequeña con relación a la proporción de propietarios en la población nativa. En cuanto a ocupación, la proporción de asalariados entre migrantes antiguos se asemeja a la proporción entre la población nativa. Por su parte, la proporción de empleadores y trabajadores por cuenta propia es mayor entre migrantes antiguos. Finalmente, el perfil educativo de los migrantes antiguos muestra una mayor proporción de personas con título universitario y una menor proporción de personas con educación primaria o menos. Esta descripción coincide con la de los migrantes recientes; sin embargo, las diferencias son mayores entre los migrantes recientes y la población nativa.

En suma, existen pequeñas diferencias entre los migrantes colombianos recientes y la población ecuatoriana en términos de estado civil, nivel educativo e inserción en el mercado laboral. Estas diferencias disminuyen cuando se analiza a los migrantes antiguos. Solo permanecen diferencias en términos de estado civil entre las mujeres. En materia de tipo de hogar y propiedad de la vivienda, se ven diferencias importantes en la medida en que los migrantes son más propensos a vivir en hogares "no convencionales" (multifamiliares o con jefatura de familia fuera del núcleo familiar). Estas diferencias disminuyen considerablemente en los migrantes antiguos, pero su distancia respecto de la población nativa permanece. Por estas razones, consideramos que la migración de colombianos al Ecuador puede caracterizarse como una migración de baja selectividad, inserción cultural y laboral fuerte y diferenciada por sexo.

\section{Chile: inicio de una historia migratoria, colombianos altamente seleccionados}

Tanto los hombres como las mujeres colombianas con experiencia migratoria reciente en Chile tienen una menor probabilidad de estar dentro de una unión marital y una mayor probabilidad de estar solteros(as). Al igual que en Ecuador, estas diferencias 


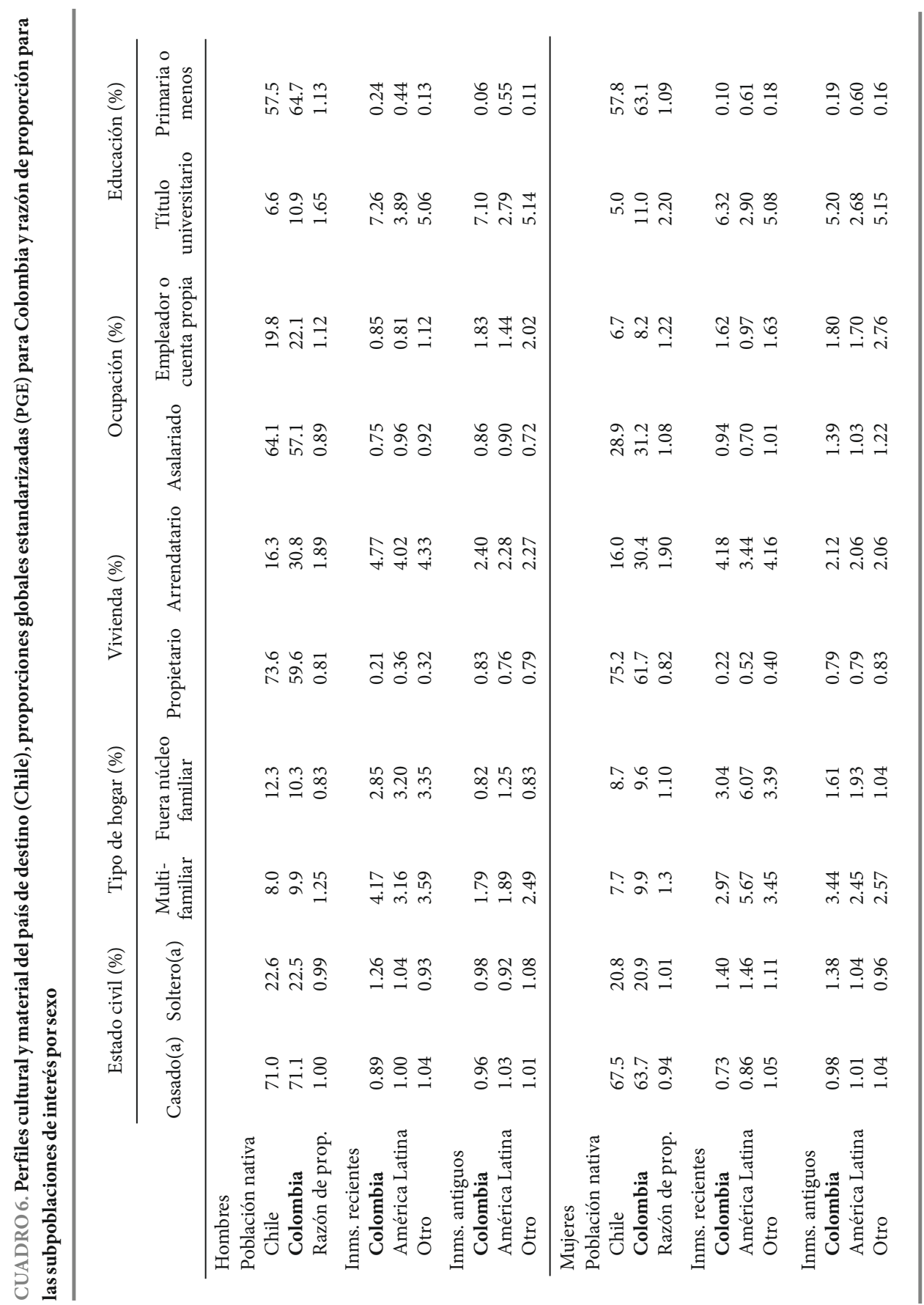


entre migrantes y población nativa son mucho más marcadas para las mujeres. A diferencia de lo que ocurre en Ecuador, estas diferencias son grandes. Los hogares multifamiliares son mucho más comunes entre los migrantes (hombres y mujeres), así como la proporción de hombres y mujeres que residen en hogares cuyo jefe no pertenece a su núcleo familiar.

Los migrantes recientes tienen una menor probabilidad de ser propietarios que las personas nacidas en Chile. Consecuentemente, la forma más prevalente de acceso a la vivienda entre migrantes recientes colombianos es el arrendamiento. La proporción de hombres asalariados es menor entre los migrantes que entre los hombres nacidos en Chile. Para las mujeres, por el contrario, las proporciones de asalariadas son similares. En cuanto a empleadores y trabajadores por cuenta propia, los migrantes son menos propensos a estar clasificados en esta categoría que los hombres nacidos en Chile, mientras que las mujeres ocupan con mayor frecuencia estas posiciones que sus contrapartes chilenas. El alto nivel educativo de los migrantes recientes constituye su característica más distintiva con respecto a la población nativa. Casi la mitad de los hombre (48\%) y un tercio de las mujeres colombianas (31\%) con experiencia migratoria reciente en Chile tienen título universitario. Estas proporciones contrastan con la prevalencia de la educación universitaria en ambos países (7 \% en Chile y $11 \%$ en Colombia). Así mismo, la proporción de personas (hombres y mujeres) con educación primaria o menos es sustancialmente más baja entre la población migrante ( $14 \%$ y $6 \%$ para hombres y mujeres, respectivamente) que entre la población chilena (aproximadamente $58 \%$ para ambos sexos).

En cuanto a los migrantes antiguos, la proporción de hombres casados y solteros se asemeja fuertemente a la observada en la población nativa (razón de proporciones igual a 0.98). Para las mujeres, por el contrario, la proporción de casadas es similar, pero la de mujeres solteras sigue siendo mayor entre las migrantes. Este resultado indica que la experiencia migratoria difiere según el sexo, pues los niveles de similitud con la población nativa no son los mismos al paso del tiempo para hombres y mujeres. En forma similar, la proporción de hombres que viven en hogares multifamiliares disminuye cuando se comparan migrantes recientes con antiguos. La razón de proporciones entre cada una de estas poblaciones y la población nativa es de 4.2 para migrantes recientes y 1.8 para antiguos. En el caso de las mujeres no ocurre lo mismo, la razón de proporciones es similar para las migrantes recientes (3) y para las antiguas (3.4).

La proporción de propietarios está positivamente correlacionada con el tiempo de residencia en el país (e inversamente correlacionada con el arrendamiento), es decir, la proporción de propietarios de vivienda es mayor entre migrantes antiguos que entre recientes. Este resultado es similar a lo encontrado en Ecuador, con la diferencia de que en Chile el incremento en la proporción de propietarios de vivienda de los 
migrantes antiguos con respecto a los recientes es más grande. Mientras que en Ecuador persisten diferencias del orden del $40 \%$ y $50 \%$, en Chile son del orden del 20 $\%$. Adicionalmente, la proporción de propietarios de vivienda en la población chilena es superior a la de Ecuador, lo que refuerza la particularidad del caso de los colombianos en Chile.

Para los hombres con más de cuatro años en Chile, la proporción de asalariados es menor que la proporción de asalariados tanto en Colombia como en Chile, lo que refleja dificultades de acceso al mercado laboral. Contrariamente, la proporción de empleadores y trabajadores por cuenta propia es mayor entre los migrantes que entre ambas poblaciones nativas. El caso de las mujeres es distinto, pues entre las mujeres migrantes antiguas ambas proporciones (asalariadas y empleadoras o trabajadoras por cuenta propia) son mayores que las proporciones observadas en Chile. Finalmente, la alta selectividad de la migración en términos educativos se mantiene entre los migrantes antiguos, lo cual indica que la migración colombiana a Chile ha sido, en forma sostenida, de personas en su mayoría con educación secundaria y una proporción con título universitario que supera la proporción de personas con dicho nivel en el país de destino.

En resumen, la población de colombianos que emigraron a Chile es distinta de la que emigró al Ecuador. La alta selectividad en términos educativos y de estado civil parece estar asociada con un nivel de convergencia mayor en términos de acceso a vivienda. Estas condiciones permiten caracterizar la migración colombiana en Chile como altamente selectiva, con diferencias importantes en la inserción cultural y laboral por sexo y con mayores niveles de acceso a vivienda por parte de migrantes antiguos.

\section{Estados Unidos: el sueño americano, asimilación media-alta}

Los migrantes colombianos recientes en EUA tienen, al contrario de los que emigraron a los dos países latinoamericanos descritos, mayor probabilidad de estar casados y menor de estar solteros que la población nativa. Las PGE de hombres casados y mujeres casadas entre los migrantes recientes se aproximan más a las proporciones observadas en la población de no migrantes en Colombia. Respecto al hogar, la proporción de personas que viven en hogares con un jefe fuera de su núcleo familiar o en un hogar multifamiliar es mayor entre migrantes que entre la población nativa. Al igual que en los dos países latinoamericanos, estas diferencias son más pronunciadas entre los hombres. La proporción de hombres en hogares multifamiliares es mayor, lo cual indica que la experiencia migratoria comienza en forma distinta con respecto a la de las mujeres. 


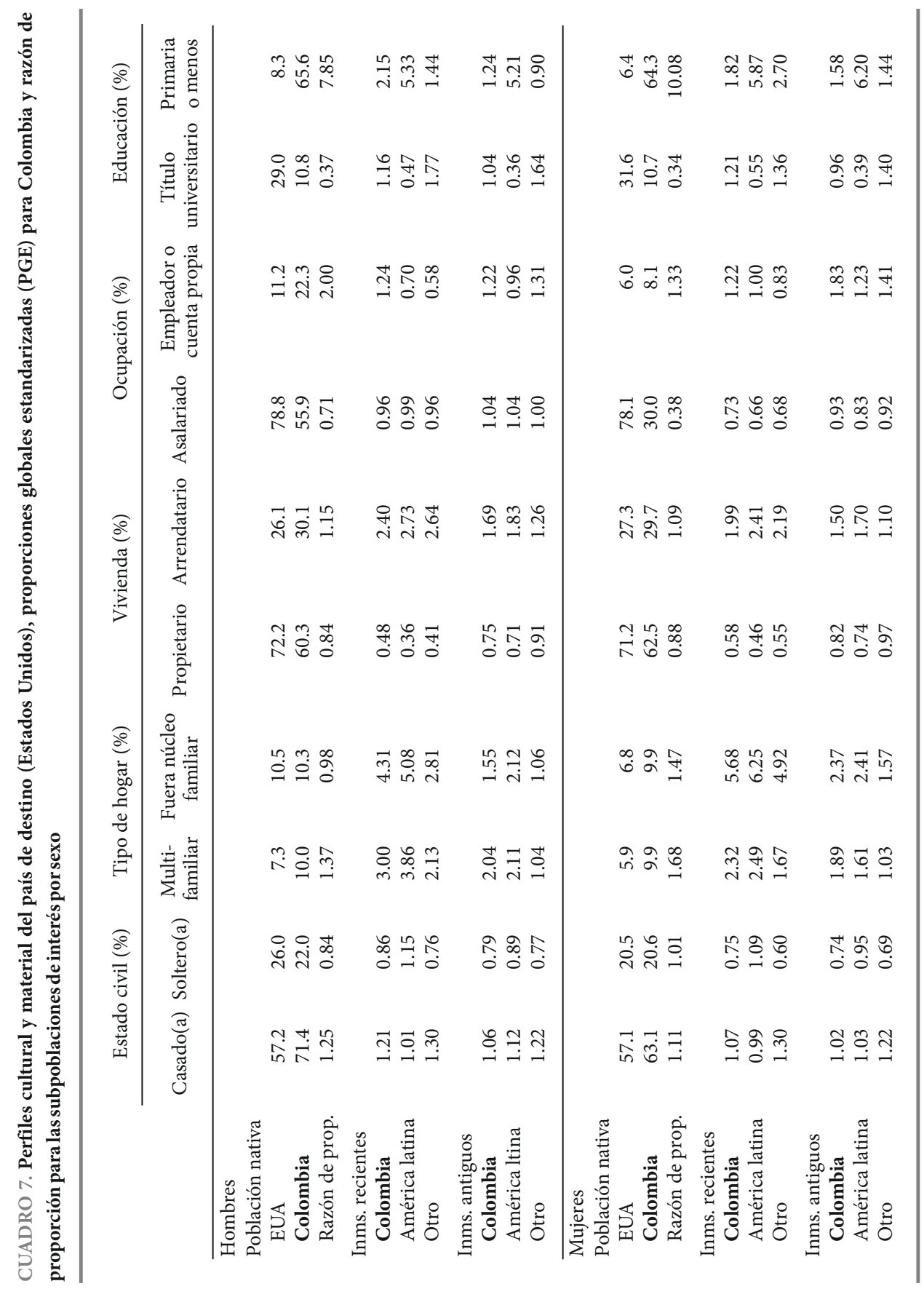


La probabilidad de tener vivienda propia es mucho menor para los migrantes recientes que para los nativos; sin embargo, la razón de proporciones es dos veces más grande entre los migrantes en EUA ( 0.48 y 0.58 para hombres y mujeres, respectivamente) que para los migrantes recientes en Chile ( 0.22 y 0.21$)$, país con un nivel comparable de propietarios entre la población nativa. En forma consistente, la proporción de arrendatarios es mayor entre los migrantes recientes y la población estadounidense. Es notable que las mujeres migrantes tengan una mayor probabilidad de ser propietarias que los hombres migrantes.

Los nativos estadounidenses tienen unas condiciones muy similares entre hombres y mujeres en términos de trabajo asalariado, mientras que los migrantes colombianos conservan una diferencia grande entre sexos en este indicador: $75 \%$ de los colombianos migrantes recientes trabaja como asalariado, mientras que $56 \%$ lo hace entre las colombianas. Es notable que, en ambos casos, estos porcentajes superan a los observados en la población colombiana no migrante (56 \% y $30 \%$, respectivamente). La proporción de empleadores o trabajadores por cuenta propia es menor entre los migrantes recientes que entre la población no migrante colombiana, y ligeramente mayor que entre la población estadounidense.

Por último, en materia de educación, la población con título universitario tiene un nivel muy similar entre hombres y mujeres tanto entre nativos como entre migrantes recientes, lo que indica un alto nivel de selección en términos educativos. Las diferencias más grandes se encuentran entre colombianos con distinto estatus migratorio. Entre aquellos recién llegados, sobre todo las mujeres, la proporción de personas con título universitario es considerablemente mayor que entre la población colombiana no migrante. La proporción de migrantes recientes con educación primaria o menor es alta en comparación con la de EUA, pero baja si se compara con los niveles observados en Colombia. Menos del $20 \%$ de los hombres y menos del $15 \%$ de las mujeres con experiencia migratoria reciente tiene un nivel de escolaridad igual o inferior a la primaria; niveles que contrastan con el $66 \%$ y $64 \%$ de hombres y mujeres con baja escolaridad en Colombia, respectivamente. Es importante notar que la proporción más alta entre las categorías de la variable de nivel educativo entre los migrantes es la de educación secundaria.

$\mathrm{Al}$ observar estos indicadores entre los migrantes antiguos se nota un nivel de convergencia tanto en hombres como en mujeres en la PGE de personas casadas. Debido a que la prevalencia del matrimonio es menor en EUA que en Colombia (57 \% vs. $71 \%$ entre ellos y $57 \%$ vs. $63 \%$ entre ellas), esta convergencia implica que los migrantes antiguos colombianos en EUA tienen una menor probabilidad de estar casados que la población colombiana no migrante. Además, la proporción de personas solteras no difiere sustancialmente entre migrantes recientes y antiguos, lo cual 
indica que la reducción en la PGE asociada al matrimonio se debe a un incremento en separaciones y divorcios entre los migrantes antiguos. Esta característica de los migrantes antiguos es particular para el caso estadounidense.

La PGE de hogares multifamiliares entre los migrantes antiguos es menor que la PGE para migrantes recientes. Esta diferencia indica que, al igual que en los otros dos países analizados hasta ahora, el tiempo de residencia en EUA esta negativamente correlacionado con la residencia en hogares multifamiliares. En forma similar, la PGE de personas que viven en hogares cuyo jefe(a) de hogar no pertenece a su núcleo familiar disminuye drásticamente con el tiempo de permanencia en EUA. Sin embargo, aun entre los migrantes antiguos estas PGE superan las proporciones observadas en ambas poblaciones no migrantes (Colombia y EUA).

La PGE de propietarios aumenta significativamente entre los migrantes antiguos. La razón de PGE para los hombres pasa de 0.48 entre migrantes recientes a 0.75 entre migrantes antiguos. En el caso de las mujeres el cambio va de 0.58 a 0.82 . A pesar de este aumento, la prevalencia de la propiedad de la vivienda entre los migrantes antiguos sigue siendo menor que entre las poblaciones de origen y destino. Las cifras de arrendamiento se comportan de manera coherente con los cambios en las PGE de propiedad debido a que otras formas de acceso a la vivienda son muy poco prevalentes.

En términos de mercado laboral, la convergencia en la PGE de asalariados se observa tanto en hombres como en mujeres, mientras que la PGE de empleadores y trabajadores por cuenta propia se incrementa en forma leve. Respecto al nivel educativo, los migrantes colombianos antiguos son similares a la población estadounidense en cuanto a la proporción de personas con título universitario en ambos sexos. Al mismo tiempo, los migrantes antiguos difieren en términos de la población con educación primaria o menos tanto de los nativos estadounidenses (mayores valores) como de los migrantes recientes (menores valores). Esto indica que la migración antigua fue predominantemente de personas con educación secundaria.

En conclusión, los migrantes colombianos en EUA parecen más propensos a estar casados en los años que siguen a la migración. Posteriormente esta prevalencia disminuye, lo cual indica una mayor prevalencia en el rompimiento de las relaciones maritales conforme aumenta el tiempo en EUA. Cuando se compara la migración reciente con la antigua en el acceso a la vivienda y al mercado laboral, se observan dos aspectos importantes. Primero, las condiciones de los migrantes recientes que van a EUA son mejores que las de los migrantes recientes a otros países. Segundo, estos indicadores mejoran entre los migrantes antiguos, lo que en muchos casos disminuye en forma sustancial las diferencias entre los sexos en el lugar de origen. En términos educativos, tanto la migración antigua como la reciente está dominada por personas 
con nivel educativo medio (educación secundaria); sin embargo, una proporción significativamente alta de migrantes recientes tiene título universitario. En suma, la migración de colombianos a EUA puede caracterizarse como una migración con niveles medios de inserción en términos culturales y materiales con diferencias importantes por sexo, que tienden a igualar los indicadores entre hombres y mujeres.

\section{España: obstáculos para la inserción en un país disímil}

La prevalencia del matrimonio entre los colombianos con experiencia migratoria reciente en España es menor que la prevalencia del mismo tanto en la sociedad de origen como en la de destino. Este resultado es mucho más acentuado entre las mujeres. Mientras que la PGE de las casadas en Colombia supera el $60 \%$, entre las migrantes recientes no alcanza el $40 \%$. En el caso de la PGE de solteros, estas proporciones alcanzan valores de $36 \%$ para hombres y $37 \%$ para mujeres, lo que sugiere una mayor prevalencia de separación o divorcio entre las mujeres ( $25 \%)$ en comparación con los hombres $(6.5 \%)$.

Los hogares multifamiliares son muy poco comunes en España; por lo tanto, la población de migrantes se distingue fuertemente de la nativa por la alta prevalencia de este tipo de hogares. En particular, la PGE de hogares multifamiliares entre los migrantes colombianos en España es la más alta de los cuatro países aquí analizados, lo que constituye una característica importante de la migración hacia este destino. En forma consecuente, la PGE de personas que viven en hogares cuya jefatura está ocupada por un miembro de fuera del núcleo familiar es alta en comparación con las sociedades de origen y destino, sin diferencias marcadas entre los dos sexos.

Como en los demás países, la PGE de propietarios es baja para los migrantes recientes. Vale destacar que en los casos de Chile y España las PGE de propietarios de vivienda son particularmente bajas entre los migrantes recientes, con una ligera ventaja entre las mujeres que emigraron a España $(20 \%)$. En consecuencia, la PGE de migrantes colombianos que viven en arriendo en España es alta, pues llega a $85 \%$ entre hombres y $75 \%$ entre mujeres.

En términos de ocupación, la migración reciente de colombianos en España está positivamente correlacionada con el trabajo asalariado, con diferencias importantes entre sexos. En el caso de los hombres, la PGE de asalariados entre los migrantes supera en forma leve a la PGE de la población no migrante colombiana y se encuentra por debajo de la proporción en la población española. En el caso de las mujeres, la PGE entre las migrantes recientes es mayor que la PGE en ambas sociedades (origen y destino). En comparación con los demás destinos analizados en este artículo, la PGE de migrantes recientes en la categoría de empleadores y trabajadores por cuenta propia es 


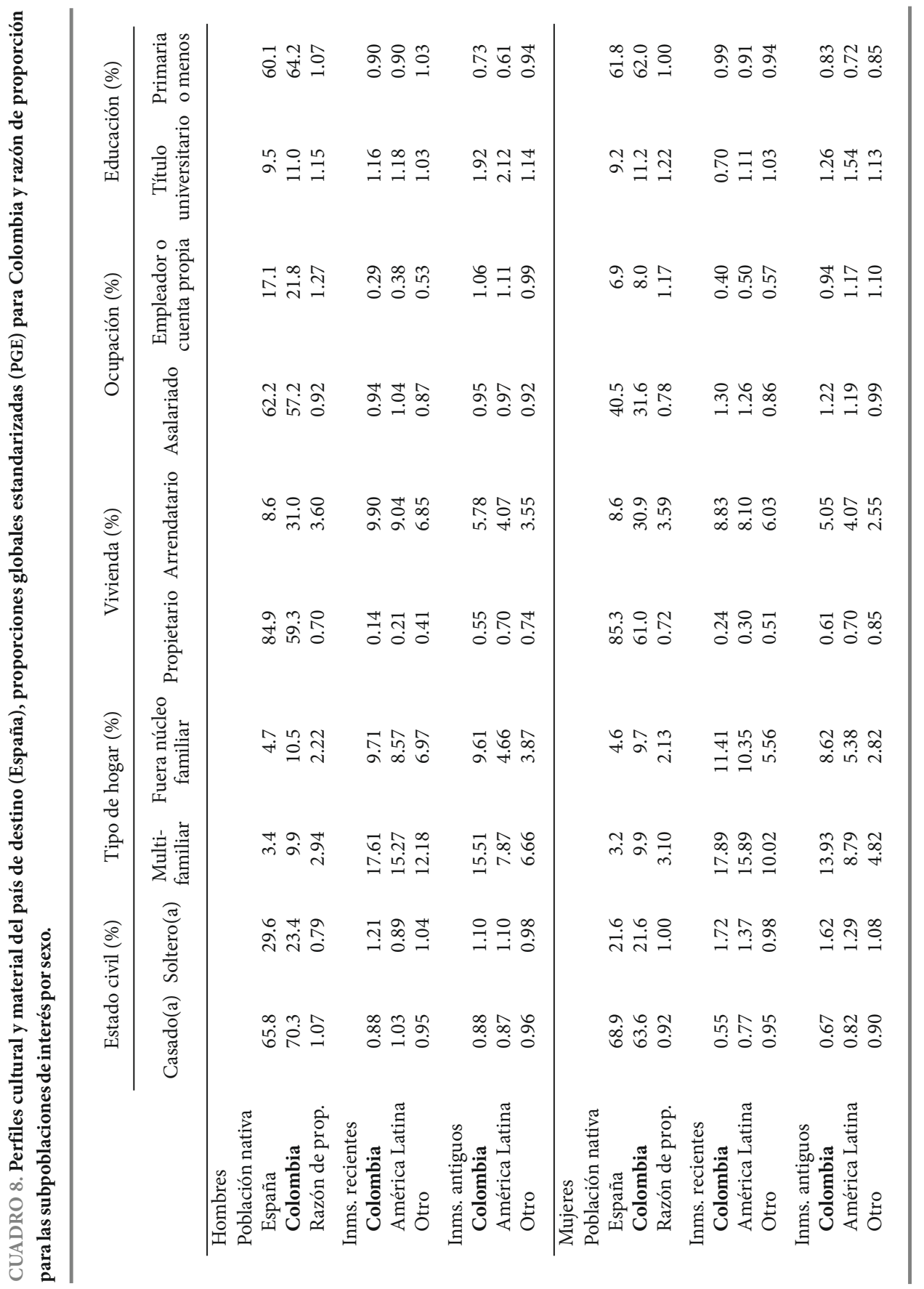


sustancialmente menor. Apenas $5 \%$ entre hombres y $3 \%$ entre mujeres, porcentajes que también contrastan con la prevalencia de esta categoría en las sociedades de origen y destino.

En términos educativos, las diferencias entre sexos en la PGE de migrantes colombianos con título universitario son sustanciales. Mientras que para los hombres esta PGE es de $11 \%$ ( $16 \%$ más grande que la proporción entre la población española), para las mujeres esta proporción es de apenas el $6.4 \%$ (30 \% más pequeña que la proporción observada para la población española). Tanto para hombres como para mujeres migrantes recientes, la proporción más grande se encuentra en la categoría de educación primaria o menos (54\% hombres y $61 \%$ mujeres). Estos dos resultados indican que en la migración a España predominan las personas con bajo nivel educativo, en contraste con lo que ocurre en destinos como Chile y EUA.

$\mathrm{Al}$ analizar los migrantes antiguos con respecto a los recientes no se observan grandes cambios en estado civil entre los hombres, mientras que entre las mujeres se nota un aumento en la PGE de mujeres casadas. Sin embargo, aun entre los migrantes antiguos la prevalencia del matrimonio sigue siendo menor que la prevalencia del mismo en las poblaciones de origen y destino, mientras que la prevalencia de la soltería es mayor con respecto a las dos mismas poblaciones. A pesar de la reducción en la prevalencia de hogares multifamiliares, este tipo de organización familiar mantiene prevalencias elevadas con respecto a la población española. Esta diferencia es más marcada entre los hombres. Un comportamiento similar se observa en la PGE de personas que residen con un jefe de hogar que no pertenece a su núcleo familiar.

Entre los migrantes antiguos, las PGE de asalariados(as) no varían sustancialmente con respecto a las de los migrantes recientes, mientras que la proporción clasificada en la categoría de empleadores y trabajadores por cuenta propia aumenta, pues se acerca, para ambos sexos, a las proporciones observadas entre la población española. La PGE de personas con título universitario entre los migrantes antiguos es mayor que la proporción de personas con este título entre la población española, aspecto que distingue esta población de la población de migrantes recientes, en especial a las mujeres. Sin embargo, la población con educación primaria o menos también es mayoría entre migrantes antiguos, como lo es entre migrantes recientes. Esto parece indicar una característica particular y sostenida de la migración a España.

En resumen, los migrantes colombianos en España tienen características muy distintas con respecto a las de los migrantes en otros países. Baja prevalencia del matrimonio, alta prevalencia de hogares multifamiliares y bajo nivel educativo. Estas diferencias son más acentuadas entre las mujeres, aspecto que refuerza resultados previos que apuntan a la heterogeneidad de la experiencia migratoria entre los sexos. En cuanto a la inserción, el caso de España presenta niveles más bajos que los otros 
países. La migración de colombianos a España se puede caracterizar como una migración de baja selectividad, bajos niveles de inserción cultural y amplias diferencias entre hombres y mujeres que tienden a ampliar las brechas entre los sexos.

\section{Conclusiones}

Son dos los dos rasgos principales de la dinámica migratoria colombiana en los cuatro destinos analizados. En primer lugar, el predominio de la población femenina, junto con diferencias importantes entre los sexos en términos de las características de selección de migrantes, y los procesos de inserción cultural y material. En otras palabras, la experiencia migratoria de los colombianos sucede de manera distinta entre hombres y mujeres. En segundo lugar, la amplia diversidad en términos de las formas de organización familiar y aspectos socioeconómicos de la población migrante y su correlación con destinos migratorios específicos. En los párrafos siguientes se desarrollan los detalles y las implicaciones de estos dos resultados.

En el caso del predominio de la población femenina, a excepción de la migración reciente en Chile, en todos los demás destinos las mujeres son mayoría entre la población migrante colombiana. Este rasgo es particularmente marcado en la migración a España. En el caso de Ecuador, las diferencias entre las experiencias migratorias de hombres y mujeres tienden a mantener las diferencias por sexo observadas en la población colombiana no migrante. En el caso de Chile y España, estas experiencias diferenciadas amplían la distancia entre los sexos, lo cual tiene consecuencias desfavorables para las mujeres. Solo en el caso de EUA la migración parece contribuir al cierre de estas brechas, en particular en aspectos de participación laboral, resultado que ha sido identificado por estudios sobre la migración entre México y EUA (Parrado \& Flippen, 2005).

Respecto a la diversidad de formas de organización familiar, los aspectos socioeconómicos de la población migrante y su correlación con destinos migratorios específicos, en EUA y Chile, en su mayoría, los migrantes ocupan posiciones sociales privilegiadas gracias a sus características socioeconómicas, por lo que existe una fuerte selección positiva en términos educativos y de acceso a vivienda. Sin embargo, una diferencia importante entre ambos destinos es la prevalencia del matrimonio: menor entre colombianos en Chile que en EUA. Esto parece indicar que un destino migratorio más distante está más correlacionado con una migración familiar que con una migración individual. En Ecuador la situación de la mayoría de los migrantes colombianos es precaria, la mayoría de la población tiene niveles educativos bajos y la prevalencia de la propiedad de la vivienda es baja. España es un caso similar al caso 
ecuatoriano, con la diferencia de que la selección negativa es mucho más acentuada entre las mujeres.

Los patrones de inserción también muestran una amplia heterogeneidad entre los cuatro destinos analizados. En términos de estado civil, el tiempo después de la migración está positivamente correlacionado con una mayor similitud entre población migrante y nativa. El caso de las mujeres en Chile y España constituye una excepción importante a este patrón, aspecto que refuerza nuestra conclusión acerca de las diferencias por sexo de la experiencia migratoria. Así mismo, EUA es un caso particular pues el mayor grado de similitud parece asociado a un incremento en divorcios y separaciones, contrario a la dinámica de los otros países, donde la convergencia entre las poblaciones emerge de una mayor prevalencia del matrimonio entre los migrantes. En cuanto a tipos de hogar, nuevamente, los migrantes antiguos tienen formas de organización de la vida en familia que se aproximan a los de la población nativa; sin embargo, estos nunca llegan a ser idénticos pues los hogares no convencionales son más prevalentes entre los migrantes. El caso extremo de esta situación se puede observar en España, y su opuesto en el Ecuador.

En términos laborales, la heterogeneidad entre los cuatro países es menor, en parte porque los motivos principales de migración son económicos, lo cual hace que la población migrante tenga una alta probabilidad de estar en el mercado laboral. Sin embargo, las diferencias existentes reflejan las distancias descritas entre los países en términos de mayores oportunidades en países como EUA y Chile, y condiciones económicas más adversas en Ecuador y España. En la misma forma, esta dimensión parece albergar las diferencias más amplias entre hombres y mujeres, con la sola excepción del caso estadounidense.

La cercanía con el Ecuador, la larga historia del conflicto colombiano y las condiciones precarias de la población rural de Colombia pueden explicar gran parte de la selectividad negativa de los colombianos que se dirigen al país vecino. Por otra parte, la atracción por el sistema educativo y el mercado laboral estadounidense, la necesidad de saber un segundo idioma y la larga historia de formación de las elites colombianas en las universidades norteamericanas pueden explicar la selección positiva de esta población - este resultado se acentúa por la selectividad negativa que caracteriza el retorno de colombianos desde EUA, como lo evidencia uno de los estudios aquí citados. Algo similar parece estar ocurriendo en Chile, donde las oportunidades de estudio y profesionales atraen población estudiantil o altamente calificada; sin embargo, la cantidad de colombianos es aún pequeña, por lo que el sesgo asociado al retorno es potencialmente menor. Finalmente, España parece estar dominada por una migración familiar fuertemente femenina; nuestra capacidad para explicarlo es más limitada pues sus características no son fáciles de vincular con causas conocidas de migración. 
Nuestro estudio comparativo de estos cuatro destinos devela la gran complejidad de la emigración colombiana. Si bien el poder explicativo de este esfuerzo de comparación es limitado, es posible derivar implicaciones tanto para el ámbito académico como para el de la política migratoria nacional. En términos académicos, tanto la teoría como los esfuerzos empíricos por conocer mejor a la población emigrante requieren un mayor desarrollo. Son necesarios estudios específicos que profundicen en casos particulares, así como la inclusión de más dimensiones de análisis; por ejemplo, salud, mortalidad, fecundidad, retorno, composición familiar, etc. En el ámbito de la política, consideramos que cualquier política migratoria colombiana debe tener en cuenta esta diversidad y orientar los esfuerzos a que estos patrones divergentes de selección e inserción puedan traducirse en beneficios para el país, o por los menos logren reducir potenciales efectos adversos como rompimiento de lazos familiares, pérdida de mano de obra, etcétera.

\section{Referencias}

Acosta, F. (2003). La familia en los estudios de población en América Latina: estado del conocimiento y necesidades de investigación. Papeles de Población, 9(37).

Álvarez Llanos, J. (2012). Inmigración colombiana en España: fenómeno multidimensional. Económicas, 33(1), 33-46.

Beauchemin, C. (2014). A manifesto for quantitative multi-sited approaches to international migration. International Migration Review, 48(4), 921-938.

Bermúdez, A. (2006). Colombian migration to Europe: political transnationalism in the middle of conflict. Centre on Migration, Policy and Society-University of Oxford, Working Paper No. 39.

Billari, F. C. \& Kohler, H.-P. (2004). Patterns of low and lowest-low fertility in Europe. Population Studies, 58(2), 161-176.

Bourdieu, P. (1996). Distinction. A social critique of the judgement of taste. Cambridge, Mass.: Harvard University Press.

Cárdenas, M., Medina, C., \& Trejos, A. (2010). Measuring economic and social impacts of migration in Colombia: New evidence. Working paper 601, 1-54.

Cárdenas, M. \& Mejía, C. (2006). Migraciones internacionales en Colombia?: ¿qué sabemos? Documentos de trabajo, 30. Bogotá. Recuperado de http://www20. iadb.org/intal/catalogo/PE/2009/02989.pdf [consultado el 15 de noviembre de 2017].

Careja, R. \& Emmenegger, P. (2012). Making democratic citizens. Comparative Political Studies, 45(7), 875-902. Recuperado de http://journals.sagepub.com/ 
10.1177/0010414011428591 [consultado el 15 de noviembre de 2017].

Cohen, J. H. (2001). Transnational migration in rural Oaxaca, Mexico: dependency, development, and the household. American Anthropologist, 103(4), 954-967.

Donato, K. M., Hiskey, J., Durand, J., \& Massey, D. S. (2010). Migration in the Americas: Mexico and Latin America in comparative context. The Annals of the American Academy of Political and Social Science, 630(1), 6-17.

Durand, J. (2009). Processes of migration in Latin America and the Caribbean (19502008). United Nations Development Programme, Human Development Reports, Research Paper 2009/24.

Feagin, J. \& Feagin, C. (2003). Adaptation and conflict: racial and ethnic relations in theoretical perspective. En Feagin, J. \& Feagin,C., Racial and ethnic relations.(pp. 22-48) New Jersey: Prentice Hall.

Garay, L. J. \& Rodríguez, A. (2005). La emigración internacional en el área metropolitana centro occidente de Colombia: caracterización socioeconómica de la población emigrante y evaluación del impacto de las remesas internacionales. Bogotá: Gobierno de Colombia, Organización Internacional para las Migraciones.

Guarnizo, L. E., Sanchez, A. I., \& Roach, E. M. (1999). Mistrust, fragmented solidarity, and transnational migration: Colombians in New York City and Los Angeles. Ethnic and Racial Studies, 22(2), 367-396.

Guzmán, J., Rodríguez, J., Martínez, J., Contreras, J. M., \& González, D. (2006). The demography of Latin America and the Caribbean since 1950. Population-E, 61(5-6), 519-576.

Héritier, F. (1996). Masculin/feminin I. La pensée de la différence. Paris: Odile Jacob.

Johnson-Hanks, J. A., Bachrach, C. A., Morgan, S. P., \& Kohler, H.-P. (2011). Understanding family change and variation: toward a theory of conjunctural action. Springer.

Kohler, H. \& Anderson, T. (2016). Divergent demographic destinies. Trabajo presentado en el 2016 Population Association of America Annual Meeting, Washington, D. C. Recuperado de htpp://paa.comfex.com/paa/2016/ meetingapp.cgi/Paper/7980 [consultado el 15 de noviembre de 2017].

Levitt, P. \& Lamba-Nieves, D. (2011). Social remittances revisited. Journal of Ethnic and Migration Studies, 37(1), 1-22.

Mcilwaine, C., (2005). Coping practices among Colombian migrants in London. London: Department of Geography-Queen Mary, University of London.

Medina, C. \& Posso, C.M. (2009). Colombian and South American immigrants in the United States of America: education levels, job qualifications and the decision to go back home. Banco de la República-Colombia, Working paper 572. 
Mejía, W. (2006). Colombianos organizados en el exterior y transnacionalismo. En Actas $52^{\circ}$ Congreso Internacional de Americanistas - Migraciones latinoamericanas: génesis y evolución de las comunidades transnacionales (pp. 59-67). Sevilla: Universidad de Sevilla.

Mejía, W. (2010). Panorama del retorno reciente de migrantes internacionales a Colombia. En VI Jornada Fundación Carolina: Migración y Desarrollo Humano (pp. 1-22). Barranquilla: Universidad del Norte.

Mejía, W. (2012). Colombia y las migraciones internacionales. Evolución reciente y panorama actual a partir de las cifras. Revista Interdisciplinar da Mobilidade Humana, 39, 185-210.

Minnesota Population Center (2015). Integrated Public Use Microdata Series, International: Version 6.4. [Machine-readable database]. Minneapolis: University of Minnesota.

Parrado, E. A. \& Flippen, C. A. (2005). Migration and gender among Mexican women. American Sociological Review, 70(4), 606-632.

Perilla, C. (2011). Migración, desarrollo humano e internacionalización. En Said, E. (ed.), Migración, desarrollo humano e internacionalización (pp. 7-19). Barranquilla: Universidad del Norte.

Portes, A. (2006). Institutions and development: a conceptual analysis. Population and Development Review, 32(2), 233-262.

Portes, A. \& Zhou, M. (1993). The new second generation: segmented assimilation and its variants. The Annals of the American Academy of Political and Social Science, 530(1), 74-96.

Postgrado en Ciencias del Desarrollo (2008). Migración forzada de colombianos al Ecuador. Umbrales, 17.

Preston, S., Guillot, M., \& Heuveline, P. (2001). Demography: measuring and modeling population processes. Oxford: Blackwell.

Ramírez, C., Zuluaga, M., \& Perilla, C. (2010). Perfil migratorio de Colombia. Bogotá: Organización Internacional para las Migraciones.

Segovia, J. S. \& Lufin, M. (2013). Approaches to the Afro-Colombian experience in Chile: South-South immigration toward the Northern regions. Journal of Black Studies, 44(3), 231-251.

Viuche, A. (2015). Entre utopías y realidades: ¿qué significados le otorga un/a colombiano(a) al hecho de vivir en Santiago de Chile? Búsquedas Políticas, 4, 925.

World Bank (2011). Global bilateral migration database, http://data.worldbank. org/data-catalog/global-bilateral-migration-database 


\section{Apéndice}

\section{CUADRO A1. Distribución porcentual de la población migrante por década de llegada para los cuatro destinos}

\begin{tabular}{|c|c|c|c|c|c|c|c|c|}
\hline \multirow{2}{*}{$\begin{array}{l}\text { Década } \\
\text { de } \\
\text { llegada }\end{array}$} & \multicolumn{4}{|c|}{ Total (miles) } & \multicolumn{4}{|c|}{ Porcentaje por década } \\
\hline & Chile & Ecuador & España & EUA & Chile & Ecuador & España & EUA \\
\hline 1900 & - & - & 1 & - & - & - & 0.0 & - \\
\hline 1910 & - & - & 9 & 14 & - & - & 0.4 & 0.0 \\
\hline 1920 & 3 & - & 23 & 79 & 1.5 & - & 1.1 & 0.2 \\
\hline 1930 & 3 & - & 35 & 97 & 2.0 & - & 1.6 & 0.2 \\
\hline 1940 & 5 & 2 & 38 & 500 & 2.8 & 0.9 & 1.8 & 1.1 \\
\hline 1950 & 8 & 2 & 74 & 1,603 & 4.6 & 1.2 & 3.4 & 3.6 \\
\hline 1960 & 7 & 5 & 199 & 3,065 & 4.1 & 2.8 & 9.3 & 6.9 \\
\hline 1970 & 11 & 10 & 281 & 5,390 & 6.4 & 6.2 & 13.2 & 12.2 \\
\hline 1980 & 26 & 11 & 297 & 8,353 & 15.3 & 6.8 & 13.9 & 18.9 \\
\hline 1990 & 75 & 21 & 938 & 12,295 & 44.7 & 12.8 & 44.0 & 27.9 \\
\hline 2000 & 31 & 116 & 239 & 12,740 & 18.6 & 69.3 & 11.2 & 28.9 \\
\hline Total & 167 & 167 & 2,134 & 44,135 & 100 & 100 & 100 & 100 \\
\hline
\end{tabular}

